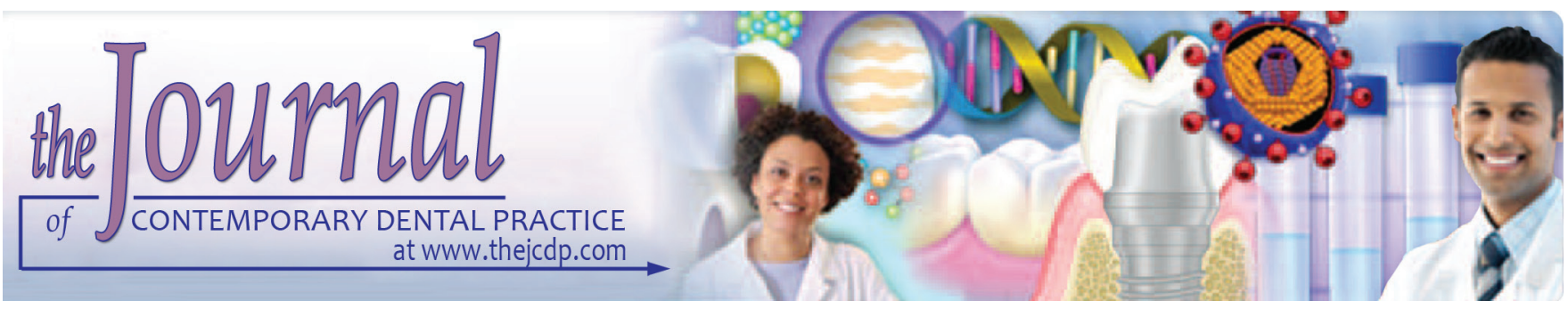

\title{
Quantitative Assessment of apically Extruded Bacteria using different Instrumentation Techniques and Preparation Taper
}

${ }^{1}$ Harsh Priyank, ${ }^{2}$ Vinisha Pandey, ${ }^{3}$ Achla Sethi, ${ }^{4}$ Vinay J Sharma, ${ }^{5}$ Harleen Bali, ${ }^{6}$ Ramandeep S Punia

\begin{abstract}
Background: Cleaning and shaping of the pulp canal is one of the most important steps of endodontic therapy. Serious complications occur by the apical extrusion of bacteria during the instrumentation procedures. Both crown-down (CD) and full-length linear motion (FM) techniques are routinely used as a component of taper rotary instrument procedures for achievement of thorough cleaning and shaping of the pulp canal space. Hence, we aimed for this study to assess the change in the amount of apically extruded bacteria using CD and FM instrumentation techniques produced by differences in taper between the instruments used during biomechanical preparation of root canals.
\end{abstract}

Materials and methods: The present study included assessments of 132 extracted maxillary central incisor teeth. To achieve a uniform teeth length of $21 \mathrm{~mm}$, the height of the tooth crown was reduced for preserving the coronal portion of teeth. A modified glass vial model was constructed for the estimation of amount of bacterial extrusion through the apical region. For filling of each pulp canal specimen, $20 \mathrm{~mL}$ of Enterococcus faecalis suspension

\footnotetext{
${ }^{1}$ Department of Conservative Dentistry and Endodontics Hazaribag College of Dental Sciences and Hospital, Hazaribagh Jharkhand, India

2Department of Conservative Dentistry and Endodontics, Institute of Dental Studies \& Technologies, Modinagar, Uttar Pradesh, India

${ }^{3}$ Department of Conservative Dentistry and Endodontics, Swami Devi Dyal Hospital \& Dental College, Panchkula, Haryana, India

${ }^{4}$ Department of Conservative Dentistry and Endodontics, SMBT Institute of Dental Sciences \& Research, Nashik, Maharashtra India

${ }^{5}$ Private Practice, Department of Oral Medicine, Diagnosis and Radiology, Jammu, Jammu and Kashmir, India

${ }^{6}$ Department of Oral Medicine and Radiology, Dasmesh Institute of Research \& Dental Sciences, Faridkot, Punjab, India
}

Corresponding Author: Harsh Priyank, Department of Conservative Dentistry and Endodontics, Hazaribag College of Dental Sciences and Hospital, Hazaribagh, Jharkhand, India Phone: +919501544877, e-mail: drharshpriyank@gmail.com was used followed by the use of a number $10 \mathrm{~K}$-file for carrying the bacteria down the lengths of pulp canals. All the contaminated teeth specimens were divided into six study groups with groups I to III containing specimens prepared in the CD manner, while groups IV to VI contained specimens prepared in the FM manner. Six teeth were taken as negative control with three specimens with each technique, and another six specimens were taken as positive controls. Cultivable bacterial counts were determined by evaluating $100 \mathrm{~mL}$ saline solution from each vial followed by its inoculation on blood agar. All the colony-forming unit (CFU) values were log-transformed (base 10), and the results were analyzed by Statistical Package for the Social Sciences software.

Results: A significantly lower quantity of CFU values was observed during $C D$ instrumentation procedures with 0.02 files in comparison with all other study groups. However, while comparing both the instrumentation procedures when different taper files, other than 0.02 taper, were used for biomechanical preparation of root canal, nonsignificant results were obtained.

Conclusion: With 0.02 taper preparations, significantly less amount of extrusion of bacteria is associated when done with CD technique.

Clinical significance: No change in the amount of apical extrusion of bacteria will be seen by changing the type of instrumentation procedures. Amount of bacteria extruded can be minimized using 0.02 taper.

Key words: Bacteria, Instrumentation, Taper.

How to cite this article: Priyank H, Pandey V, Sethi A, Sharma VJ, Bali H, Punia RS. Quantitative Assessment of apically Extruded Bacteria using different Instrumentation Techniques and Preparation Taper. J Contemp Dent Pract 2017;18(9):826-830.

Source of Support: Nil

Conflict of Interest: None

\section{INTRODUCTION}

One of the most important component steps for the successful completion of root canal therapy is the complete and thorough cleaning and shaping of root canal space for the purpose of removal of inflamed and necrotic pulpal tissue. ${ }^{1}$ During the process of root canal instrumentation, 
the following components can be extruded beyond the apical foramen:

- Dentinal chips

- Root canal tissue fragments

- Necrotizing and inflamed tissue

- Intracanal medicaments

- Microorganisms

This can impose a serious problem as the apically extruded necrotic materials and microorganisms can cause posttreatment pain or a flare-up. ${ }^{2}$ Although these risk factors are significantly decreased by an accurate control of the working length, periapical extrusion of these components can result in serious posttreatment complications, such as flare-ups, pain, and swelling, which can further result in extreme discomfort to the patients resulting in inter-appointment emergency. ${ }^{3}$ In the present treatment scenario, apical extrusion of debris is associated with all types of preparation techniques and instrumentation procedures. This occurs even with clinicians prepare the root canal short of the apical terminus. ${ }^{4}$

Both crown-down (CD) and full-length linear motion (FM) techniques are routinely used as a component of taper rotary instrument procedures for the achievement of thorough cleaning and shaping of the pulp canal space. Literature quotes that significantly less bacterial extrusion is associated with $\mathrm{CD}$ preparation techniques in comparison with FM instrumentation. ${ }^{5}$ There is paucity of studies in the literature that have assessed the impact of pulp canal taper on the apical extrusion of necrotic debris and bacteria. Hence, we aimed for this study to assess the change in the amount of apically extruded bacteria using $\mathrm{CD}$ and FM instrumentation techniques produced by the difference in taper between the instruments used during biomechanical preparation of root canals.

\section{MATERIALS AND METHODS}

This study was conducted in the Department of Conservative Dentistry and Endodontics of the dental institute, and included the assessment of 132 extracted maxillary central incisor teeth. All the teeth, after extraction, were immediately placed in normal saline solution for storage. Inclusion criteria for the present study included:

- Single-rooted maxillary central incisors

- Teeth with straight pulp canals

- Teeth with initial apical diameter approximate to International Organization for Standardization size \#15 K-file

All the extracted teeth were cleaned carefully for removing any remnants of bone, calculus, and necrotic or physiologic soft tissue. Periodontal curettes were used for removing these fragments. To achieve a uniform teeth length of $21 \mathrm{~mm}$, the height of the tooth crown was reduced for preserving the coronal portion of teeth. The crown portion was preserved because it acts as a reservoir for irrigation solution. Expiration of the root canal remnants was done with the help of a barbed broach, and $1 \mathrm{~mm}$ short of apex (apical foramen), the working length was evaluated. Cyanoacrylate glue was used for sealing the root ends of the entire teeth specimen once they were dried. This was done for creation of a reservoir in root canals for contamination with a suspension of Enterococcus faecalis. Construction of a modified glass vial model was done for the estimation of amount of bacterial extrusion through the apical region. A hole was created through the center with the purpose of holding the tooth specimen in an upright position. Insertion of the tooth specimens into the rubber stoppers under pressure was performed, and glue was used for fixing the samples to the stoppers through their cementoenamel junction. For the prevention of bacterial microleakage, the vials were coated on their outer surfaces by two to three coats of nail varnish. The entire system was then sterilized for obtaining a contamination-free environment. For equalization of the pressure inside and outside the vial, a sterile 27 -gauge needle was inserted alongside the rubber stopper. From fresh 24-hour bacteria grown in brain-heart infusion broth, a standard suspension of $E$. faecalis was formulated. For ensuring the bacterial concentration of $1.5 \times 10^{8}$ colony-forming units (CFUs) mL ${ }^{-1}$, adjustment of the turbidity of the suspension was done. About $20 \mathrm{~mL}$ of E. faecalis suspension was used for filling of each pulp canal specimen, followed by use of a number $10 \mathrm{~K}$-file for carrying the bacteria down the lengths of pulp canals. This was followed by incubation of the infected pulp canal specimens at $37^{\circ} \mathrm{C}$ for 24 hours. Filing of the vials was done with $10 \mathrm{~mL}$ of saline solutions before the commencement of the instrumentation procedure of root canals. For the creation of a standard apical patency, placement of a sterile number $15 \mathrm{~K}$-file was done $1 \mathrm{~mm}$ beyond the apical foramen. All the contaminated teeth specimens were divided into six study groups as shown in Table 1 , with 20 specimens in each group. In groups I to III, preparation of the canals was done in the CD manner, while in the groups IV to VI, preparation of the canals was done in the FM manner. Six teeth were taken as negative control (noninfected) with three specimens with each technique,

\begin{tabular}{llc}
\multicolumn{2}{c}{ Table 1: Distribution of samples into various study groups } \\
\hline Groups & Technique & Taper \\
\hline I & CD & 0.02 \\
II & CD & 0.04 \\
III & CD & 0.06 \\
IV & FM & 0.02 \\
V & FM & 0.04 \\
VI & FM & 0.06 \\
\hline
\end{tabular}


and another six specimens were taken as positive controls (previously infected). After the completion of pulp-canal preparation procedure, cultivable bacterial counts were determined by evaluating $100 \mathrm{~mL}$ saline solution from each vial followed by its inoculation on blood agar with the help of the quantitative inoculation technique. ${ }^{6,7}$ Following incubation at $37^{\circ} \mathrm{C}$ for 24 hours, calculation of the CFUs for each tooth specimen was done. For statistical analysis, all the CFU values were log-transformed (base 10), and the results were analyzed by Statistical Package for the Social Sciences software version 16.0. Student's t-test and Tukey's honest significant difference test were used for the assessment of the level of significance. The $p<0.05$ was taken as significant.

\section{RESULTS}

Distribution of all the specimens in various groups is shown in Table 1. Table 2 highlights the mean values and standard deviation in all the experimental groups. No growth was observed in the negative control group, while a positive bacterial growth was associated in all the positive control groups during assessment after experimental time interval. A significantly lower quantity of

Table 2: Correlation of distribution of apically extruded E. faecalis (CFU mL ${ }^{-1}$ )

\begin{tabular}{lllll}
\hline Groups & & $\begin{array}{l}\text { Mean } \pm \text { standard } \\
\text { deviation }\end{array}$ & Minimum & Maximum \\
\hline I & CD-02 & $2.25^{1} \pm 0.16$ & 1.25 & 3.15 \\
II & CD-04 & $2.81^{2} \pm 0.12$ & 2.18 & 3.46 \\
III & CD-06 & $2.84^{2} \pm 0.09$ & 2.22 & 3.39 \\
IV & FM-02 & $2.87^{2} \pm 0.12$ & 2.25 & 3.24 \\
V & FM-04 & $2.93^{2} \pm 0.50$ & 1.92 & 3.64 \\
VI & FM-06 & $2.99^{2} \pm 0.11$ & 2.39 & 3.34
\end{tabular}

Difference in superscripts shows statistically significant difference among various sample groups $(p<0.05)$
CFU values was observed during CD instrumentation procedures with 0.02 files in comparison with all other study groups $(\mathrm{p}<0.05)$ (Table 2 and Graph 1$)$. However, no statistically significant results were obtained while comparing both the instrumentation procedures when different taper files, other than 0.02 taper, used for biomechanical preparation of root canal $(p>0.05)$.

\section{DISCUSSION}

In the presence of dense inflammatory cell infiltrate and intense immune response, pain and clinical swellings usually accompany the extrusion of cellular debris and microorganisms in the apical areas during the process of cleaning and shaping the root canals. The mechanical cleaning process of the pulp canals is often associated with this undesired consequence, and none of the techniques of cleaning and shaping of root canals avoids apical debris extrusion. ${ }^{8}$ Therefore, routine investigation is carried out in search of a technique that avoids such negative consequences. Variation has been seen in the amount of debris extruded apically, which further depends on the kinematics, amount of root canal filing done, taper, cross-section, and efficacy of the files used for preparing the root canal. ${ }^{9}$ Hence, we aimed for the present study to assess the change in the amount of apically extruded bacteria using CD and FM instrumentation techniques produced by differences in taper between the instruments used during biomechanical preparation of root canals.

In this study, we used three different types of taper systems, i.e., 0.02, 0.04, and 0.06 (Table 1). Apical extrusion of all the bacteria resulted from all the instrumentation types and procedures. With the exceptions of results obtained with 0.02 taper preparations, no significant results were obtained while comparing the amount of bacterial extrusion in different types of taper and with

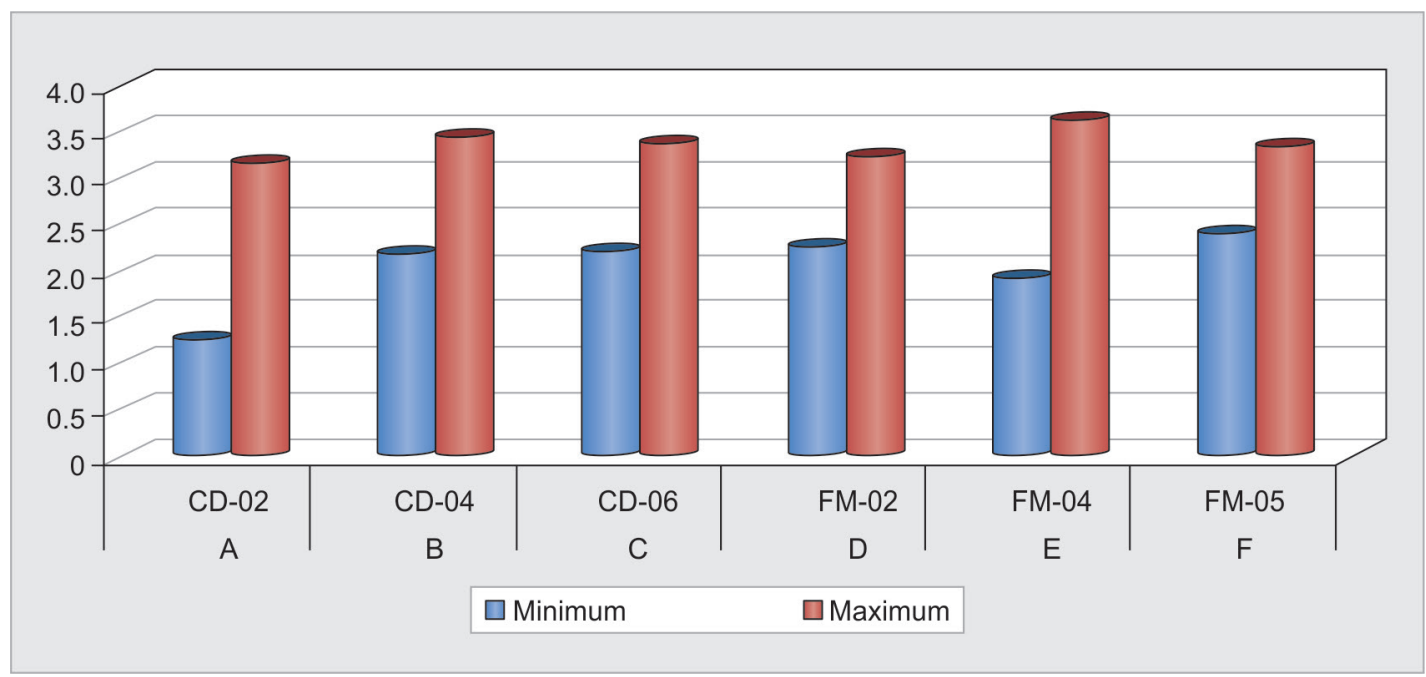

Graph 1: Descriptive values of distribution of apically extruded E.faecalis (CFU mL-1) 
CD and FM instrumentation approaches (Table 2). Our results were in correlation with the results obtained by Aksel et al, ${ }^{7}$ who observed similar findings in their study. Nevares et $\mathrm{al}^{8}$ evaluated and compared the amount of debris extruded periapically in canals prepared by various systems used in reciprocating and continuous motions. They analyzed 60 mandibular teeth, and divided them randomly into three study groups with 20 specimens in each group. These groups were the Reciproc (REC) group, WaveOne (WO) group, and HyFlex CM (HYF) group respectively. On an analytical balance, one Eppendorf tube per tooth was examined and weighed. As per manufacturer's instructions, pulp canals were instrumented. To a total of $9 \mathrm{~mL}, 2.5 \%$ sodium hypochlorite solution was used for standard irrigation. Incubation of the teeth specimens after removal from the Eppendorf tubes was done at $37^{\circ} \mathrm{C}$ for 15 days for evaporating the liquid. They again weighed the tubes and noted and calculated the difference between the initial and final weights. They observed that apical extrusion of debris resulted from all the three types of systems. However, significantly more debris was produced by REC system in comparison with the WO system. In comparison with the HYF system, both the other systems produced significantly higher amount of extrusion of debris apically. Aksel et $\mathrm{al}^{7}$ assessed the impact of various root canal instrumentation techniques and preparation tapers on the quantity of bacteria extruded apically. They assessed a total of 98 extracted mandibular incisor teeth, which were contaminated with E. faecalis suspension. Following incubation at $37^{\circ} \mathrm{C}$ for one full day, instrumentation of the pulp canals was done with $\mathrm{K} 3$ rotary files in CD or FM techniques with three different types of taper. They collected apically extruded bacteria into saline solution-containing vials, and incubated the microbial specimens in brain-heart agar medium for 24 hours and assessed the numbers of CFUs. They observed that when prepared with 0.02 taper, significant differences occurred. From the results, they concluded that when prepared with 0.04 and 0.06 taper, instrumentation technique did not appear to have a significant effect on the amount of bacterial extrusion. Surakanti et $\mathrm{al}^{10}$ evaluated the quantity of debris extruded apically during the biomechanical preparation of root canal with two different instrumentation systems - rotary and reciprocating nickel-titanium. They assessed 60 mandibular first premolars and divided them randomly into 3 study groups with 20 specimens in each group. They instrumented the root canals with WaveOne ${ }^{\mathrm{TM}}$ system, and full-sequence rotary HyFlex $\mathrm{CM}^{\mathrm{TM}}$ and ProTaper ${ }^{\mathrm{TM}}$ instruments. Using bidistilled water, they irrigated the canals. They collected apically extruded debris in preweighed Eppendorf tubes, and compared the initial values and values after collection. They observed significantly more debris with
WaveOne ${ }^{\mathrm{TM}}$ and ProTaper ${ }^{\mathrm{TM}}$ rotary instruments in comparison with HyFlex $\mathrm{CM}^{\mathrm{TM}}$ rotary instruments. From the results, they concluded that less extrusion of debris apically occurs with the full-sequence rotary instrumentation. Kustarci et $\mathrm{al}^{11}$ assessed and compared the quantity of debris extruded apically using $\mathrm{K} 3$, protaper rotary instruments, and manual step-back technique in 45 extracted human teeth. They divided all the specimens into three study groups with 15 specimens in each group. The three study groups consisted of specimens instrumented with $\mathrm{K} 3$, protaper rotary instruments, and K-type stainless steel instruments respectively. From the results, they concluded that significantly more debris was extruded apically with protaper rotary instruments. Garlapati et $\mathrm{al}^{12}$ assessed the amount of apical extruded bacteria during pulp canal preparation process with four rotary instrumentation techniques. After assessing a total of 50 extracted human mandibular premolars, they observed a significant difference in the amount of CFUs between the four experimental rotary nickel-titanium instrumentation groups. From the results, they concluded that among all their study groups, minimal bacterial extrusion occurred in K3 group, while Mtwo group was associated with maximum bacterial extrusion.

\section{CONCLUSION}

Significantly less amount of extrusion of bacteria is associated with 0.02 taper preparations when done with CD technique. No significant change in the amount of extruded bacteria occurs with an increase in taper from 0.04 to 0.06 irrespective of the type of technique for root canal preparation. However, future studies are required for better exploration of this field of dentistry.

\section{REFERENCES}

1. Stewart GG. The importance of chemomechanical preparation of the root canal. Oral Surg Oral Med Oral Pathol 1955 Sep;8(9):993-997.

2. Seltzer S, Naidorf IJ. Flare-ups in endodontics: I. Etiological factors. J Endod 1985 Nov;11(11):472-478.

3. Siqueira JF Jr. Microbial causes of endodontic flare-ups. Int Endod J 2003 Jul;36(7):453-463.

4. Tanalp J, Güngör T. Apical extrusion of debris: a literature review of an inherent occurrence during root canal treatment. Int Endod J 2014 Mar;47(3):211-221.

5. Tinoco JM, De-Deus G, Tinoco EM, Saavedra F, Fidel RA, Sassone LM. Apical extrusion of bacteria when using reciprocating single-file and rotary multifile instrumentation systems. Int Endod J 2014 Jun;47(6):560-566.

6. Er K, Sümer Z, Akpinar KE. Apical extrusion of intracanal bacteria following use of two engine-driven instrumentation techniques. Int Endod J 2005 Dec;38(12):871-876.

7. Aksel H, Küçükkaya Eren S, Çakar A, Serper A, Özkuyumcu C, Azim AA. Effect of instrumentation techniques and preparation taper on apical extrusion of bacteria. J Endod 2017 Jun;43(6):1008-1010. 
8. Nevares G, Xavier F, Gominho L, Cavalcanti F, Cassimiro M, Romeiro K, Alvares P, Queiroz G, Sobral AP, Gerbi M, et al. Apical extrusion of debris produced during continuous rotating and reciprocating motion. Sci World J 2015 Sep;2015:267264.

9. Braga LC, Faria-Silva AC, Buono VT, de Azevedo Bahia MG. Impact of heat treatments on the fatigue resistance of different rotary nickel-titanium instruments. J Endod 2014 Sep;40(9): 1494-1497.

10. SurakantiJR, Venkata RC, Vemisetty HK, Dandolu RK, Jaya NK, Thota S. Comparative evaluation of apically extruded debris during root canal preparation using ProTaper ${ }^{\mathrm{TM}}, \mathrm{HyFlex}^{\mathrm{TM}}$ and WaveOne $^{\mathrm{TM}}$ rotary systems. J Conserv Dent 2014 Mar;17(2): 129-132.

11. Kustarci A, Akdemir N, Siso SH, Altunbas D. Apical extrusion of intracanal debris using two engine driven and step-back instrumentation techniques: an in-vitro study. Eur J Dent 2008 Oct;2(4):233-239.

12. Garlapati R, Venigalla BS, Patil JD, Raju RV, Rammohan C. Quantitative evaluation of apical extrusion of intracanal bacteria using K3, Mtwo, RaCe and protaper rotary systems: an in vitro study. J Conserv Dent 2013 Jul;16(4):300-303. 